\title{
ETHICS
}

\section{Children of the 90s: ethical guidance for a longitudinal study}

\author{
S E Mumford
}

\section{Introduction}

Children of the Nineties (ALSPAC) is a major longitudinal study of pregnancy and childhood. From its beginnings in 1990, it has had its own multidisciplinary ethics and law committee, with several interesting features. The committee is specific to this study and has a broad remit which has allowed it to be involved in planning the study as a whole, approving individual projects, and responding to ethical issues as they arise.

This article is the first of two covering the early work of the committee, the decision to establish a separate ethics committee and its initial role in formulating policies for ethical conduct in obtaining data from questionnaires, biological samples, and clinical and environmental tests. The intention is to offer readers the opportunity to consider theoretical questions of ethics in epidemiological research against the perspective of the real issues faced by one committee. By looking at the way in which this committee's policies evolved, others may find useful strategies for dealing with similar dilemmas.

\section{The nature of the study}

Children of the Nineties or ALSPAC (the Avon Longitudinal Study of Pregnancy and Childhood) is a major epidemiological study of the 14000 babies born in the Bristol area between April 1991 and December 1992. ${ }^{1}$ The study began in pregnancy and will follow the children up to age 7 and beyond; dozens of research groups have already made use of the ALSPAC data, investigating a variety of facets of child health and development.

ALSPAC data come from several sources: a succession of postal questionnaires ask detailed questions about the mother's background, health and lifestyle, and about the child's environment and development. Partners are also given questionnaires through the mothers. Samples of maternal blood taken in routine antenatal testing and blood from the umbilical cord have been stored for the extraction of DNA and other tests. Measurements are taken in the in the home-for example, of the temperature of the baby's room and the presence of radon gas. Finally, a 10 per cent sample of the children are given clinical examinations, including tests of cognition, vision, and hearing and blood tests for iron deficiency anaemia.

\section{The Ethics Committee}

Although there is little English law specifically relating to medical research, circulars issued by the Department of Health have made obligatory the establishment of local research ethics committees for the purposes of evaluating research proposals. ${ }^{2}$ There is also guidance from international codes and from professional bodies on the conduct of research involving human subjects. Most of this is primarily concerned with clinical trials and may seem to be of little relevance to non-invasive cohort studies of the type contemplated by ALSPAC. However, the 1991 guidelines of the Council for International Organizations of Medical Sciences (CIOMS) ${ }^{3}$ provide an ethical framework specifically for epidemiological research.

How much regulation of epidemiological research is actually necessary? Levine ${ }^{4}$ and Rothman $^{5}$ have suggested that the complicated procedures necessary for obtaining approval for large scale but trivial and non-invasive studies mean that epidemiologists are fast becoming an "endangered species." The guidelines and procedures used by research ethics committees do not always lend themselves to this sort of research. ${ }^{6}$ For example, cohort studies are usually classified as non-therapeutic and so may be inappropriately subjected to the rigorous conditions designed for drug trials or liver biopsies.

On the other hand, it seems wrong to assert that merely asking questions or making use of a little surplus blood, needs no ethical scrutiny. The questions posed by ALSPAC may concern drug taking and sexual abuse, and improper use of the answers could have serious repercussions for those concerned. The British Medical Association stresses the need for doctors to keep the public's confidence by seeking ethical approval before distributing questionnaires or interviewing subjects. ${ }^{7}$ There has traditionally been less insistence on ethics committee approval for the use of existing tissue samples. ${ }^{8}$ However, the storage of 28000 blood samples for genetic testing could, if unsupervised, pose major threats to participants and society.

The CIOMS guidelines recommend that there should be a formal review process for epidemiological studies. The use of rigorous ethical criteria may also actually contribute to the success of a project in the same way that patient cooperation assists in treatment. Those who are treated as respected participants in research will understand it better, trust the 
researchers more, and appreciate why decisions have been made. ${ }^{9}$ This in turn should, of course, increase the accuracy and pertinence of the information obtained. ${ }^{6}$

All ALSPAC projects must be referred to the relevant local research ethics committees. However, the ALSPAC Steering Committee decided that, because of the breadth and length of this study and the multiplicity of potential ethical issues, the study should also have its own ethics and law committee. The composition of this committee falls within the CIOMS recommendations ${ }^{3}$ : its 10 members include medical specialists from the fields of epidemiology, obstetrics, child health and nursing and lay people, including academic lawyers and philosophers. In recognition of the importance of stakeholder participation, ${ }^{3910}$ there are also representatives of the mothers in the study. The committee meets about every two months.

One unusual feature of this committee is the breadth of its remit. Committee decisions have had a significant effect not only in rejecting or refining the design of individual protocols, but also on the shape of the study as a whole. The committee began by establishing general guidelines for the study and has subsequently dealt with the resolution and monitoring of individual cases within that framework; in some cases, it has considered the need to modify the framework itself.

\section{The ethical issues}

All scientific research on human subjects is subject to the provisions of the Declaration of Helsinki. ${ }^{11}$ These emphasise the need to protect human subjects and to ensure scientific rigour. The CIOMS guidelines for epidemiological research apply the four principles of medical ethics devised by Beauchamp and Childress $^{12}$ : autonomy, beneficence, nonmaleficence and justice. However, it may be that ethical priorities in epidemiology are subtly different from those in clinical medicine, and the weight given to one principle versus another may vary. ${ }^{13}$ It has been suggested that the model of public health may require some sacrifice of individual rights in favour of the protection of the public. ${ }^{14-16}$ Alternatively, adequate protection of persons may be achieved without insisting on the methods which prevail in clinical research; for example, there may be no need to obtain written consent from those filling in questionnaires. ${ }^{6}$

Others take the view that epidemiological research actually imposes additional ethical concerns. ${ }^{17-19}$ In Gostin's view, a "person dominated medical ethic" is insufficient for populations. For example, the principle of avoiding harm must be expanded so as to include stigmatisation of groups as well as individuals. And the very notion of harm may require a wider definition, incorporating embarrassment, ostracism, or even time spent in the research. ${ }^{20}$ Research questions should be selected and participants chosen so as to spread the benefits and burdens of research ${ }^{17}{ }^{19}$; ; findings should be reported responsibly, avoiding undue sensationalism or harm to subjects. ${ }^{18}$

\section{Good science}

It is commonly accepted that "a badly conceived trial is fundamentally unethical."."3 However, ethics committees sometimes feel uncomfortable assessing scientific validity and the more these committees are representative of the whole community, the fewer members there will be with the technical knowledge to raise questions about the scientific aspects of a project. ALSPAC has dealt with this problem by creating a Scientific Advisory Committee and a special Genetics Advisory Committee. The ethics and law committee may also invite the authors of a protocol or other experts to discuss specific concerns.

\section{Responsibility to participants}

In any research study, it is of fundamental importance that participants be respected as persons. From the outset, ALSPAC has made an effort to treat its parents and children as partners rather than merely subjects. The very practical advantages of this approach are demonstrable. The participation rate is about $87 \%$ and mothers say they enjoy taking part. In epidemiological research, the protection of participants also requires a just selection of subjects. ${ }^{320} 22$ In the case of ALSPAC, Bristol was chosen as the site of the study precisely because its population was considered representative of Britain. The decision to study all mothers and babies in the cohort further reduced the risk of prejudice.

The ethics and law committee went on to identify several areas in which there were particular concerns relating to the protection of ALSPAC participants:

Confidentiality: To what extent should information provided by the participant in a questionnaire, or gleaned in the course of an interview or examination, be kept confidential and/or anonymous?

Consent: In which aspects of the study is the consent required from adult participants and/or on behalf of the children? Must the consent be expressed or may it be implied? Ought it to be recorded in writing?

Follow up: Does the study have a responsibility to participants who may feel distressed or discover problems as a result of questions raised during the study? If so, how should this duty be discharged?

Reporting: How much information about the results of the research should be provided to participants, particularly information that may relate specifically to the health of their children?

Information: To what extent should participants be informed about the decisions taken on the matters described above? For example, if there has been a decision to respect most, but not all confidences, how should this be explained?

\section{"Just a few questions": questionnaires and interviews}

Asking questions is by no means an ethically innocuous activity, especially given the matters being investigated by ALSPAC. When questions cover sensitive subjects such as participants' relationships with their spouses and 
parents, there is a risk that some distress may result. Having a stranger invade the home environment to ask probing questions could be even more upsetting if not handled sensitively. Further harms or wrongs could result if participants' answers were made public.

PREVENTING HARM TO PARTICIPANTS: AVOIDING DISTRESS

The committee took as a starting point the guidelines of the British Psychological Society, ${ }^{24}$ which state that research should be avoided if it may cause foreseeable threats to psychological wellbeing. Care was taken to see that questions were framed sensitively, and interviewers were advised that if a participant showed any signs of discomfort, the questioning on that topic should stop and not resume.

However, some mothers seen at home might already be quite obviously distressed; others might react negatively to a question some time after the interview. Was the study's role merely to ask questions, or did it have some further obligation to these subjects? The committee endorsed the view that the expertise of study personnel lay in epidemiology and not in psychiatry. ${ }^{16}$ They could not themselves be expected to provide counselling. However, a strong argument exists that there should be "no survey without service." 25 If participants were submitting themselves and their homes for analysis in the interests of health, it would be unfair for them to suffer detriment and gain no health benefits themselves.

A partial solution was the study's decision to set up a telephone hotline, not to provide help itself, but to facilitate its provision by others. A comprehensive list was compiled of sources of assistance, from general practitioners to rape crisis centres, and at the end of each questionnaire, participants were encouraged to consult the hotline for information or to speak to their own doctor or health visitor if they had questions. Interviewers who encountered very distressed mothers were also advised to encourage them gently to seek whatever assistance was felt necessary from appropriate sources.

\section{CONFIDENTIALITY AND ANONYMITY}

The committee recognised the importance of devising a policy on the handling of information imparted to ALSPAC through questionnaires, interviews, and examinations. The most important issue was that of confidentiality: to what extent could, or should, this information be made available to outsiders?

The English law on confidentiality is in some ways curiously under developed, in part because, until the enactment of the Human Rights Act 1998, there was no general protection of a right to privacy. Cases have tended to concentrate on the breach of commercial confidential information leading to financial detriment. ${ }^{26}$ Hence the regulation of doctor-patient confidentiality has traditionally been left to the General Medical Council. The GMC is assiduous in its protection of confidentiality, but does allow for certain exceptions. For example, confidential information may be divulged, "rarely, ... on the ground that it is in the public interest...such as, for example, investigation by the police of a grave or very serious crime." ${ }^{27}$

The model of doctor and patient does not entirely fit the ALSPAC situation, in which there is no clinical relationship between the parties. Neither, however, would the relationship between the researchers and participants be analogous to that of journalists or market researchers and their subjects, when it is assumed that the information provided will be passed on to others. ${ }^{28}$ ALSPAC might be held to have a duty of confidentiality simply because the medical setting suggested that the usual doctor-patient rules applied. ${ }^{19}{ }^{29}$ In addition, the professionals involved in the study continue to be bound by their own codes of conduct. Furthermore, the CIOMS guidelines ${ }^{3}$ specify that investigators should omit identifying information and limit access to files if disclosures to third parties might cause harm or distress.

Nevertheless, there would be a legal obligation for the study to reveal accessible information if its files were requested under subpoena. (In practice, courts make an effort to resist this.) There is no legal duty to offer information, even about a crime-except under section 18 of the Prevention of Terrorism Act 1989 or in case of treason. However, the GMC rules would allow some answers to questionnaires or interviews to be divulged to the appropriate authorities if it were deemed in the public interest to do so, and specifically recommend this in the case of suspected child abuse. $^{27}$

THE QUESTIONNAIRES

The ALSPAC ethics committee accepted from the outset the necessity of adopting a policy of confidentiality in respect of questionnaire responses. The Data Protection Act 1998 requires adequate security measures to be taken to protect stored data; ALSPAC chose to protect its participants' answers by removing their names from their responses and keeping the two sets of data in separate computers. This meant that ALSPAC staff would themselves be unable to link participants with their responses. The committee accepted this policy of confidentiality reinforced by anonymity with little debate, assuming that participants would answer more freely if they knew that no one would be able to identify them with their answers. That in turn would improve the quality of the study.

Participants were therefore given a promise at the outset that all answers to questionnaires would be kept in confidence, and that the two sets of data containing their names and their answers could not be linked. Subsequent questionnaires contained a reminder that researchers would not know their identity (nor be able to respond to any questions they wrote in the margins) unless they actually chose to sign their names on a particular questionnaire. That promise reinforced the study's prima facie obligation to maintain confidentialityand added a duty to keep the identity of 
participants unknown to researchers as well as outsiders. However, this policy later presented obstacles for the study.

\section{THE INTERVIEWS}

Home interviews were set up to conduct substudies and to administer the questionnaires to those who could not speak or write English. Here, it was impossible to give a guarantee of anonymity, but the duty of confidentiality remained. However, the extent of that duty raised difficult questions: How was the interviewer to respond if she saw evidence of serious criminal behaviour or formed the view that a child might be in danger? If she was asking the same questions as the postal questionnaire, the committee saw no strong reason why the two sets of answers should be treated differently. The same guarantees of confidentiality should be given. The amount of harm that might be prevented by passing on information about a past criminal activity, for example, was not felt to outweigh the benefits of an honest response to the questions.

However, if the interviewer were to witness something that might threaten the safety of the child, to require her to maintain absolute confidentiality might be to impose an intolerable burden and cause her to breach professional guidelines about reporting suspected child abuse. Furthermore, if the ultimate end of the study was to bring about improved child health, then it was arguable that there was an ethical duty to act to prevent clear, present harm to children. The duty of fairness and openness to participants meant that some explanation was necessary. It was decided that interviewers should tell participants that anything they saw or heard would be kept confidential, except in an emergency. The committee then established a protocol for interviewers who did suspect dangerous or seriously criminal behaviour. They were to report the matter to the study director, Professor Golding. She was then to consult with the community paediatrician about any case of alleged child abuse and all such instances were to be reported to the ethics and law committee.

\section{"Just a few drops of blood": biological samples}

An important aspect of the ALSPAC research was the extraction and storage of DNA from maternal and umbilical cord blood. When blood samples are required for antenatal testing, the consent of the expectant woman is of course a prerequisite. This is often an informal process, implied from the woman offering her arm; however, in some cases, such as the blood test for $\alpha$ fetoprotein (which may indicate spina bifida in the fetus), counselling is offered before the woman is asked to consent.

Was specific consent needed in order to take, store, and test a small additional amount of the mother's blood-or that taken from the umbilical cord? Guidelines issued by the Royal College of Physicians $^{30}$ state that neither consent nor the approval of an ethics committee is necessary for the removal of "a small extra volume of blood," nor for "the anonymous use of tissues genuinely discarded in the course of medical treatment," provided that the custodian of the tissue gives consent and the recipient is bound by rules of confidentiality. Did this guidance afford sufficient protection to ALSPAC participants?

It is both a legal requirement and an affirmation of the ethical principle of respect for autonomy that consent must be given to any interference with a person's physical integrity. In the ALSPAC study, consent has already been given to the actual "interference"- the insertion of a needle. However, the mother will have no knowledge that the blood will be used for anything other than her personal therapeutic benefit and that of the child. It is important that people should be given information which will be material to their decision making. ${ }^{12} 31$ But is the question of research on a small additional amount of blood a trifling matter, and unlikely to be of consequence to participants? Does the careful protection of confidentiality afford sufficient protection against any perceived harm that might result?

The fact that the ALSPAC research includes genetic testing may be significant. The Nuffield Council on Bioethics ${ }^{32}$ and the Advisory Committee of Genetic Testing ${ }^{33}$ have both published reports which call for very specific consent to each genetic test intended. However, both these reports had as their focus the investigation of serious diseases. The Ethical, Legal and Social Impact Working Group of the National Center for Human Genome Research has suggested that there is a difference between research into high risk mutations and that investigating polymorphisms. ${ }^{34}$ When investigating the aetiology or incidence of serious disease, there may be an ethical obligation to pass on relevant information to those affected by it - and hence a corresponding obligation to seek specific prior consent to individual tests. But the genetic research proposed within ALSPAC concentrates on normal genetic variations where the information gleaned would not be of any particular benefit to individual participants. In such cases, where the research is to be done on anonymised tissue samples, the ACGT makes an exception to its stringent consent requirements.

Nevertheless, some participants may still find the idea of DNA analysis threatening and may not be reassured by guarantees of anonymity. Providing information about the research uses of the blood and asking for the agreement of participants signifies respect for autonomy and a proper involvement of the participant in the research. This applies as much to the cord blood as it does to that taken from the mother. Although the issue of interference with physical integrity does not arise, the implications, particularly of genetic testing and the information it may reveal, are not primarily connected to the technical means by which the blood was obtained. Similar ethical safeguards are thus required. 
The ethics committee decided to seek specific consent for the testing of both maternal and cord blood. Participants were told that the tissue would be stored and used for a variety of tests, amongst which genetic tests were specifically cited. This consent was formally recorded and a signature obtained from the mother.

\section{"Just a few little tests": clinical and environmental investigations}

The clinical tests of babies and the tests of the home environment are perhaps the most invasive part of the study and most closely resemble the type of research normally reviewed by ethics committees.

\section{BEST INTERESTS?}

In medical ethics, there has been a long standing dispute as to the extent to which a child may be used as a research subject in studies which are not intended to benefit that child. ${ }^{35}$ No strict insistence on the child's best interests would support the notion of one child being "used" in the interests of others. And yet, from a public health perspective, research on healthy children can provide important findings. If we are ever to allow these broader needs of child health to be fulfilled, then the best interests test must either be jettisoned, or very widely interpreted. The House of Lords did the latter in the case of $S$ v $S$, stating that, "a parent would have some regard to the general public interest and would not refuse a blood test unless he thought that would clearly be against the interests of the child." ${ }^{\text {c6 }}$

Various professional bodies have also offered their interpretation of the balance between child protection and paediatric research. The Royal College of Physicians ${ }^{37}$ and the Medical Research Council ${ }^{38}$ take the view that a limited amount of research on healthy children is permissible, but impose restrictions on it. Research which could be done on adults should never be done on children and only procedures of no more than "negligible" or "minimal" risk of harm may be carried out. The former British Paediatric Association ${ }^{39}$ additionally ruled out research of a non-therapeutic nature which would cause physical or psychological distress to the child.

ALSPAC research included taking blood from children to test for iron deficiency anaemia and hypercholesterolaemia. The BPA guidance appeared to counsel against nontherapeutic venepuncture because of the potential for psychological distress. However, the committee was informed that specially trained nurses would be taking the ALSPAC blood samples. With the use of a surface anaesthetic (Emla cream) and the distraction of watching a video, the procedure was unlikely to cause distress. ${ }^{40}$ A pilot study appeared to confirm this; members of the committee watched the testing in progress and agreed to permit these interventions.

RESULTS AND EXPLANATIONS

The extent to which results should be reported back to participants is a more peculiarly epidemiological question. Initially, the committee concentrated on findings from the analysis of questionnaires and saw a stark choice between a process which would enable information to be provided to parents and one which would adequately safeguard the confidentiality of responses. Giving information back to parents after it had been analysed would mean breaking the code; this was seen to compromise the promise of anonymity.

There was also the question of whether participants would want unsolicited bad news. In some ways, the situation was analogous to the problems faced in studying the incidence of HIV infection from anonymised blood samples. Although the protection of subjects and contacts might warrant tracing those who are HIV positive, Gillett ${ }^{41}$ and Last ${ }^{16}$ offer convincing counterarguments. Those concerned will have been given no forewarning or counselling as to what is to be revealed to them. Researchers do not have their permission to discover ethically problematic information about them. It may be that they have only agreed to give blood for testing because of a guarantee of anonymity. Society would not be better protected if research subjects stopped coming forward because of a fear of contact tracing. And society will in the end benefit from an accurate picture of the rate and spread of the disease.

For similar reasons, it was decided initially that information about children gleaned through the analysis of ALSPAC data would not be passed on to their parents. An additional relevant factor was that much of the research was designed to "test the tests." There was little that would be of use to parents in these results.

However, it was important for participants not to be lulled into a false sense of security by thinking that the investigations carried out for the study were not medical checks designed to provide health care for their children. The fact that no results were provided could not be taken as an indication that the child was alright. A statement reminding participants that study personnel would not be able to trace them and thus could not provide information or help them was included at the end of each questionnaire and mentioned again at the beginning of clinical testing.

It is difficult to know whether parents themselves would choose the same balance between anonymity and the provision of results. Subsequent events and the further exploration of this issue have led to a reconsideration of the strict decision not to provide results.

\section{Challenges for the committee}

Many of the policies originally adopted by the committee have been challenged in the light of developments in the course of the study's early years. The second article in this series will deal with the committee's response to some of these issues.

I thank Professor Jean Golding and the other members of the ALSPAC Ethics and Law Committee for their assistance. Responsibility for any errors remains my own.

The author is secretary to the ALSPAC Ethics and Law Committee. 
1 Golding J and the ALSPAC Study Team. Children of the Nineties: a resource for assessing the magnitude of pong-term effects of prenatal and perinatal events. Contem-

porary Reviews in Obstetrics and Gynaecology. 1996; 8: 89-92 Committees. 1991 Circular HSC (IS) 153.

3 Council for International Organizations of Medical Sciences (CIOMS), World Health Organization. International Guidelines for Ethical Review of Epidemiological Studies. WHO: Geneva, 1991

4 Levine R. Human Experimentation and Medical Ethics. In: Bankowski Z, Howard-Jones N, eds. XVth CIOMS Round Table Conference, 1982. Geneva: CIOMS, 1982:194.

5 Rothman KJ. The rise and fall of epidemiology: 1950-2000 A.D. $N$ Engl f Med 1981;304:600-2.

6 Capron AM. Protection of research subjects: Do special rules apply in epidemiology? $f$ Clin Epidemiol 1991;44:81S-9S.

7 British Medical Association. Keeping the Public's Confidence. London: BMA, 1989

8 Royal College of Physicians. Guidelines on the Practice of Ethics Committees on Medical Research Involving Human Subjects. London: RCP, 1989.

9 Sandman PM. Communication responsibilities of epidemiologists. F Clin Epidemiol 1991; 44:48S.

10 Ferrinho P. HIV and the epidemiologist. Lancet 1989, ii: $1523-4$

11 World Medical Association. Declaration of Helsinki 1964 (revised 1975, 1982, 1989, 1996)

12 Beauchamp TL, Childress JF. Principles of Biomedical Ethics. 4th edn. New York: Oxford University Press, 1994

13 Levine C. Ethics and epidemiology in the Age of AIDS. In: Coughlin S, Beauchamp T, eds. Ethics and Epidemiology. Oxford: Oxford University Press, 1996: 239 54.

14 Waters WE. Ethics in epidemiological research. Int $\mathcal{F}$ Epidemiol 1985; 14:48-51.

15 Charlton BG. Public health medicine - a different kind of ethics. F $R$ Soc Med 1993; 86:194-5.

16 Last JM. Epidemiology and ethics. Law, Medicine and Health Care 1991;19:166-74.

17 Nakajima H. The responsibilities of epidemiologists. Law, Medicine and Health Care. 1991; 19:164-5.

18 Gordis L. Ethical and professional issues in the changing Gordis L. Ethical and professional issues in the changing
practice of epidemiology. $\mathcal{F}$ Clin Epidemiol 1991;44:9Spractice
$13 \mathrm{~S}$.

19 Gostin L. Ethical principles for the conduct of human subject research: population-based research and ethics. Law, Medicine and Health Care 1991;19:191-201.

20 Gold EB. Confidentiality and privacy protection in epidemiological research. In: Coughlin S, Beauchamp T, eds. Ethics and epidemiology. Oxford: Oxford University Press, 1996: 128-41.
21 Coughlin S, Beauchamp T. Ethics, scientific validity and the design of epidemiologic studies. Epidemiology 1992;3:343design

22 Dickens BM. Issues in preparing ethical guidelines for epidemiological studies. Law, Medicine and Health Care 1991;19:175-83.

23 Mason JK, McCall Smith RA. Law and Medical Ethics. 4th edn. London: Butterworths, 1994:352.

24 British Psychological Society. Code of conduct, ethical principles and guidelines. London: BPS, 1998.

25 Barker DJ, Hall AJ. Practical epidemiology. 4th edn. Edibnburgh: Churchill Livingstone, 1991:96.

26 Brazier M. Medicine, patients and the law. 2nd edn. London: Penguin, 1992: 48.

27 General Medical Council. Duties of a Doctor. London: GMC: 1995.

28 Westrin C-G. The ethics of data utilisation: a comparison between epidemiology and journalism. BMF 1994; 308:522-3.

29 Beauchamp T, First three authors, please, et al. Ethical guidelines for epidemiologists. F Clin Epidemiol 1991;44 (Suppl 1):151S-69S

30 Working group to the Royal College Physicians Committee on Ethical Issues in Medicine. $f$ R. Coll Phys Lond on Ethical $1994 ; 28: 439$.

31 Sidaway v Board of Governors of the Bethlem Royal Hospital and the Maudsley Hospital [1986] AC 871.

32 Nuffield Council on Bioethics. Genetic Screening:Ethical Issues. Oxford: Nuffield Council on Bioethics, 1993.

33 Advisory Committee on Genetic Testing (Department of Health). Advice to Research Ethics Committees London: DoH:1998.

34 Clayton EW, Steinberg KK, Khoury MJ, et al. Informed consent for genetic research in stored tissue samples. consent for genetic research
$7 A M A 1995 ; 274: 1786-92$

35 Ramsey P, McCormick R. The enforcement of morals: nontherapeutic research on children. Experimentation in children: sharing in sociality. The Hastings Center Report 1976:6.

$360 . S$ v. $S$; $W$ v. Official Solicitor [1970] 3 All ER 107, at 111.

37 Royal College of Physicians. Research involving patients London: RCP: 1990

38 Medical Research Council. The ethical conduct of research on children. London: MRC, 1991.

39 British Paediatric Association. Guidelines for the ethical conduct of research using children. London: BPA, 1992.

40 Garralda E. Venepuncture distress and research in children. Lancet 1993;341:832.

41 Gillett G. HIV and the epidemiologist. Lancet $1989 ; \mathbf{i i}: 1228-9$. 